\title{
EGU2020-14098
}

https://doi.org/10.5194/egusphere-egu2020-14098

EGU General Assembly 2020

(c) Author(s) 2020. This work is distributed under

the Creative Commons Attribution 4.0 License.

\section{A Multi-model Assessment of the Changing Risks of Extreme Rainfall Events in Bangladesh under 1.5 and 2.0 degrees' warmer worlds}

\author{
Ruksana Rimi $^{1,2}$, Karsten Haustein ${ }^{1}$, Emily Barbour ${ }^{1,3}$, Sarah Sparrow ${ }^{4}$, Sihan $\mathrm{Li}^{1,4}$, David Wallom ${ }^{4}$, \\ and Myles Allen ${ }^{1}$ \\ ${ }^{1}$ University of Oxford, Environmental Change Institute, School of Geography and the Environment, Oxford, United Kingdom \\ of Great Britain and Northern Ireland (ruksana.rimi@ouce.ox.ac.uk) \\ ${ }^{2}$ Mawlana Bhashani Science and Technology University, Department of Environmental Science and Resource Management, \\ Santosh, Tangail-1902, Bangladesh. \\ ${ }^{3}$ Commonwealth Scientific and Industrial Research Organisation, Land and Water, Canberra, ACT 2601, Australia. \\ ${ }^{4}$ Oxford e-Research Centre, Department of Engineering Science, University of Oxford, Oxford, OX1 3QG, United Kingdom.
}

For public, scientists and policy-makers, it is important to know to what extent human-induced climate change played (or did not play) a role behind changing risks of extreme weather events. Probabilistic event attribution (PEA) can provide scientific information regarding this association and reveal whether and to what extent external drivers of climate change have influenced the probability of high-impact weather events. To date, most of the PEA-based studies have focused on extreme events of mid-latitudes and predominantly events that have occurred in the developed countries. Developing countries located at the tropical monsoon regions are underrepresented in this field of research, despite that fact that these countries are highly climate vulnerable, often experience extreme weather events that cause severe damages and have the least capacity to adapt.

Bangladesh, a South Asian country with tropical monsoon climate, is a hotspot of climate change impacts as it is vulnerable to a combination of increasing challenges from record-breaking temperatures, extreme rainfall events, more intense river floods, tropical cyclones, and rising sea levels. The unique geographical location of this country particularly exposes it to high risks of flooding and landslides caused by heavy rainfall events. Observation based studies indicate that the frequency of high-intensity rainfall events may have already increased, with significant repercussions for agriculture, health, ecosystems and economic development.

Using high resolution regional climate model (RCM) simulations from weather@home, here we quantify the risks of extreme rainfall events in Bangladesh under pre-industrial, present-day and future climate scenarios of the Paris Agreement temperature targets of $1.5^{\circ} \mathrm{C}$ and $2^{\circ} \mathrm{C}$ warming. Additionally, we assess the risks under greenhouse gas (GHG)-only climate scenario where anthropogenic aerosols are reduced to pre-industrial levels. In order to test the robustness of the RCM results, available four atmosphere only global circulation model (AGCM) simulations from the Half a degree Additional warming, Prognosis and Projected Impacts (HAPPI) project are analysed. This enabled for the first time, a multi-model assessment of the changing risks of extreme rainfall 
events in Bangladesh considering anthropogenic climate change drivers.

Findings suggest that both a $1.5^{\circ} \mathrm{C}$ and $2.0^{\circ} \mathrm{C}$ warmer world is poised to experience increased seasonal mean and, to a lesser extent, increased extreme rainfall events. The risk of a 1 in 100 year rainfall event under current climate condition has already increased significantly compared with pre-industrial levels. Substantial reduction in the impacts resulting from $1.5^{\circ} \mathrm{C} \mathrm{compared} \mathrm{with}$ $2^{\circ} \mathrm{C}$ warming is reported in this study; however the difference is spatially and temporally variable across Bangladesh. This paper highlights that reduction in the anthropogenic aerosols play an important role in determining the overall future climate change impacts; by exacerbating the effects of GHG induced global warming and thereby increasing the rainfall intensity. The policymakers therefore need to take stronger climate actions to avoid impacts of $2^{\circ} \mathrm{C}$ warmer world and consider future changes in the risks of extreme rainfall events in the face of changeable GHG and aerosol impacts. 